\title{
Modeling a process combining a cereal dryer with a bioenergy unit for equipment design in developing countries
}

\author{
Michel Rivier ${ }^{1,2} \odot \mid$ Antoine Collignan ${ }^{2}$ | Jean-Michel Meot ${ }^{1,2}$ | Martial Madoumier ${ }^{2}$ ( ) | \\ Patrick Sebastian $^{3}$
}

${ }^{1}$ CIRAD, UMR QualiSud, Montpellier, France

${ }^{2}$ QualiSud, Univ Montpellier, CIRAD, Montpellier SupAgro, Université d'Avignon, Université de La Réunion, Montpellier, France

${ }^{3}$ Université de Bordeaux, I2M, UMR CNRS 5295, Talence, France

\section{Correspondence}

Michel Rivier, CIRAD, UMR 95 QualiSud, 73, Rue Jean François Breton, TA B-95/15, 34398 Montpellier Cedex 5, France.

Email: michel.rivier@cirad.fr

\begin{abstract}
This study describes the development of a process model combining a biomass energy conversion unit with a cereal-based products' dryer. Heat and mass transfer and pressure drops, which occur during the process, are identified using two experimental set-ups. The tool can predict the behavior of a heat exchanger and simulate drying of agglomerated products. The model is then used to evaluate the process performance in its installation context, by means of indicators, based on which six design solutions are studied. The results obtained provide initial guidelines for installing a processing unit in the South and clearly show the usefulness of this sort of process design aid tool. It may be integrated into a multiobjective optimization environment, in order to design a high-performance process, tailored to the context of developing countries.

Practical applications

In Sub-Saharan Africa, agri-business companies carrying out drying operations are experiencing difficulties obtaining efficient equipment, providing their energy supply, and guaranteeing the quality of the finished products. Research activities have already enabled the manufacture and installation in Burkina Faso and Mali of prototype dryers built on the principle of flat-bed dryers but heated by gas combustion, an expensive and nonsustainable energy. At present, a biomass heat generator and heat exchanger still need to be manufactured locally. Hence the objective of this work is to be able to use the process model as a design aid tool for installations combining the three pieces of equipment. Local manufacturing support will be incorporated during the development of high-performance design solutions to work toward creating and installing sustainable drying units in West Africa.
\end{abstract}

\section{1 | INTRODUCTION}

Following the industrial revolution of the 19th century, food processing has become an industrialized sector in Northern countries. Technical innovations and the study and improvement of the various unit operations have enabled this change of scale. The same cannot be said for developing countries, where the processing sector represents just $6 \%$ of world turnover, for a number of inhabitants forming around $32 \%$ of the world's population (Rastoin, 2012). However, in these urbanizing countries of high demographic growth, faced with food insecurity (Jacquet, Pachauri, \& Tubiana, 2012), reinforcing the food processing sector is a major driver for development. However, companies are experiencing difficulties in getting established and consolidating. Indeed, the processes used require large material and energy resources, which are often costly. In addition, in the context of developing countries, access to water, energy, and raw materials, as well as equipment construction and maintenance, is no easy matter. These problems are recognized as major obstacles to the development of these countries (Dabat, Blin, \& Rivier, 2010; de Janvry \& Sadoulet, 2000) and weigh down on the sustainable development objectives of the industries. Hence, the creation of efficient equipment using safe and renewable energies for the processes is becoming a priority (Kyte, Clos, Amin, \& Marangoly George, 2015).

This issue can be illustrated perfectly in West Africa, with the need to design high-performance small-scale drying units. In this region of high cereal production and consumption (Kearney, 2010), as well as high postharvest losses (Affognon, Mutungi, Sanginga, \& Borgemeister, 2015), the development of drying units is a boom 


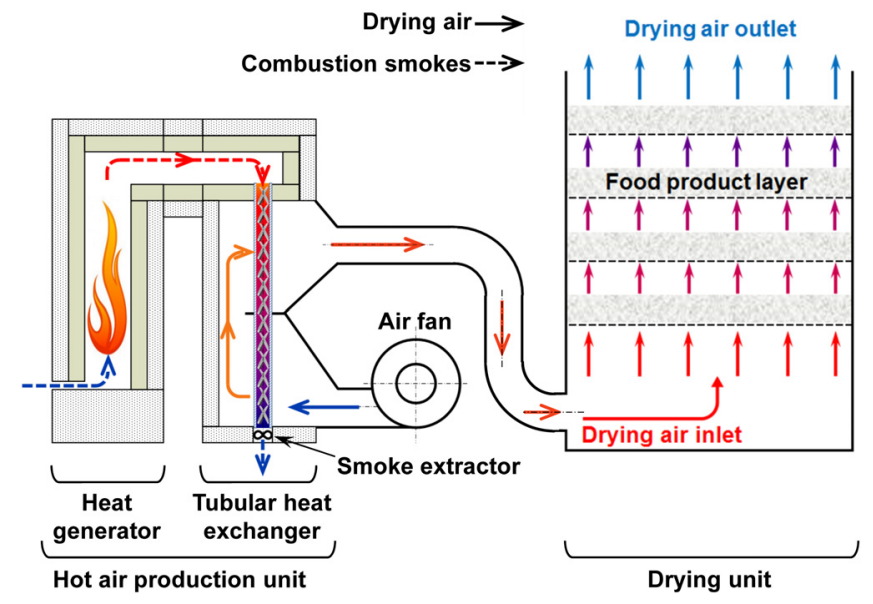

FIGURE 1 Schematic representation of the global installation

sector. Largely operating at family level, the manufacture of dried products is raising growing interest from small- and medium-sized agri-business companies. Yet the gas dryers available are characterized by low energy efficiency (Boroze et al., 2014), while this operation is classified as the most energy intensive of this food processing sector (Kerkhof \& Coumans, 2002). Conventional energies (gas, electricity) are particularly expensive and their availability is haphazard, while solar energy cannot cover demand in terms of power. Hence, the use of biomass as a fuel represents a promising energy alternative. It can be applied thanks to the by-products of agri-business processing (stones, peels, cakes, shells, etc.), which previously were very little used. Use of this biomass must be accompanied by high-performance and sustainable systems for combustion, heat transfer, and bringing the food product into contact with hot air. Yet the few currently existing installations in developing countries are under-performing.

We should recall that the performance of a drying unit is based on multiple objectives, as varied as high-quality food production, good energy efficiency and high yield, but also easy local manufacture and adaptability to the social and cultural context. Hence, given the complexity of the system, and in terms of design, the modeling tool represents a good option for determining implementation conditions tailored to the local context.

The objective of the present study is to develop a numerical simulator of the process combining a cereal dryer with a bioenergy unit in order to evaluate the performances of the design solutions. Hence, the originality of this work lies in being able to assess the process performance under multiple and original criteria, suitable for design and then optimization in a specific developing countries context.

First, the experimental set-ups used to study the main process functions are presented. The model input design and context-related variables, as well as the process performance variables, are described in detail. Then, various heat and mass transfer models are developed, as well as pressure drop models. The programming scheme setting out various models for evaluating the design solutions is described in detail. These are explained and then evaluated. Finally, the critical analysis of several design solutions shows the usefulness of this sort of tool as a design aid for units tailored to the local context.

\section{2 | MATERIALS AND METHODS}

\section{1 | Presentation of experimental set-ups}

The process studied combines a biomass energy conversion operation with a dryer (Figure 1).

Two modules perform the main functions of hot air production and drying.

A heat generator, based on the combustion of locally available biomass, produces thermal energy in the form of hot flue gases.

A heat exchanger is necessary to transfer this thermal energy to the drying air. The overall performance of the process is based on the design of a heat exchanger and dryer tailored to the local manufacturing and operating contexts in developing countries. Hence, within the framework of this study, two experimental set-ups were developed in order to identify the essential parameters for developing models for the heat exchanger and dryer and validate them.

The first set-up is based on the principle of a tubular heat exchanger (Figure 2). The latter transfers the thermal energy from the hot flue gases to a second fluid (air flow for the dryer). The principle of a tubular gas-air heat exchanger (1) was favored for application in developing countries. This type of heat exchanger is easier to manufacture, as the materials are available and there is good command of the manufacturing techniques locally. Turbulators (2) are installed in each of the tubes in order to improve thermal performance (Dewan, Mahanta, Raju, \& Kumar, 2004). The hot flue gases enter in the upper part of the tubes, at the outlet of the biomass generator. It flows through the heat exchanger tubes, before being evacuated in the lower part, either via a stack effect or with the assistance of a hot flue gas extractor. This hot flue gas circuit represents the "primary" circuit. The "secondary" circuit is the one where the ambient air enters the lower part of the heat exchanger with the assistance of an air fan. The air flow is heated by contact with the outer surface of the tube bundle in two successive passes (in the lower part and then the upper part). The heated air (drying air) is then sent to the bottom part of the dryer. The heat exchanger is not a conventional counter-flow heat exchanger. However, it is similar in terms of overall behavior. Thus, it is considered a counter-flow heat exchanger. 


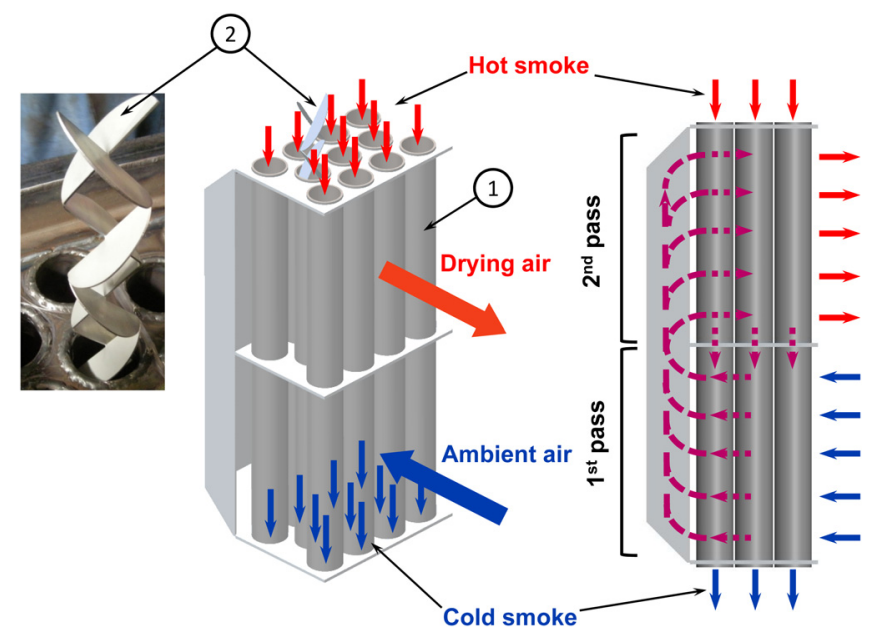

FIGURE 2 Tubular heat exchanger fitted with an elliptic shaped turbulator

The experimental set-up for characterizing the heat exchanger was developed by a previous study (Rivier, Sébastian, Goli, Raffray, \& Collignan, 2015). Here, it is used to evaluate the convection thermal exchange coefficient and the pressure drops in the heat exchanger. It is based on using an elliptic shaped turbulator. Imperfections due to local manufacture of this turbulator are reproduced in order to evaluate their impact on the performances of the heat exchanger and the process. Three different diameters were selected, corresponding to the three tube profiles most commonly used in West and Central Africa.

The second set-up is based on the principle of flat-bed dryers, forced convection dryers commonly used for drying raw cereals (Proctor, 1994). A semicontinuous packed bed dryer was designed based on this principle (Figure 3), specifically for drying processed agglomerated products.

A pilot dryer was manufactured and fitted with instruments (Figure 4) in order to identify

- pressure drops caused by the product (durum wheat couscous) throughout a drying cycle
- the heat transfer between the drying air and the agglomerates of a layer of couscous.

The product is arranged in layers a few centimeters thick, on stacked trays. The hot air flow arriving from the heat exchanger passes through the trays from bottom to top. The evaporating capacity of this air is harnessed to dehydrate the product until it reaches a stable water content. When the product in the bottom tray is dry, the tray is removed and, then, the trays above are lowered by one level; a new top tray is then reloaded with wet product.

The instrumentation installed on the dryer reads the values of the ambient air temperature and air temperature reaching the product, the ambient air relative humidity, and the static pressure under the stacked trays.

\section{2 | Choice of input variables and process performance variables}

The process coupling the biomass energy conversion unit to the dryer is defined by input variables: control variables and sizing variables, which represent the design variables, plus context-related variables,
Column 1

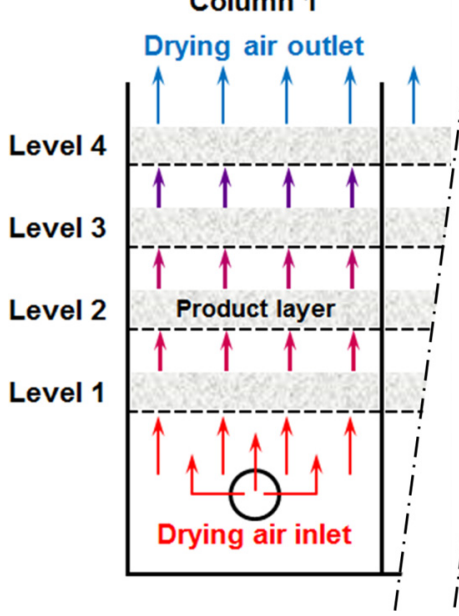

Column n

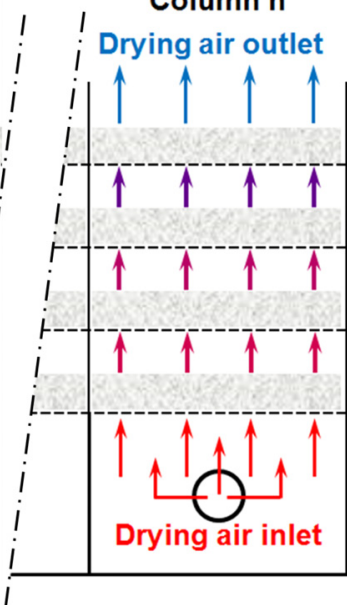

FIGURE 3 Schematic representation of the packed bed dryer 

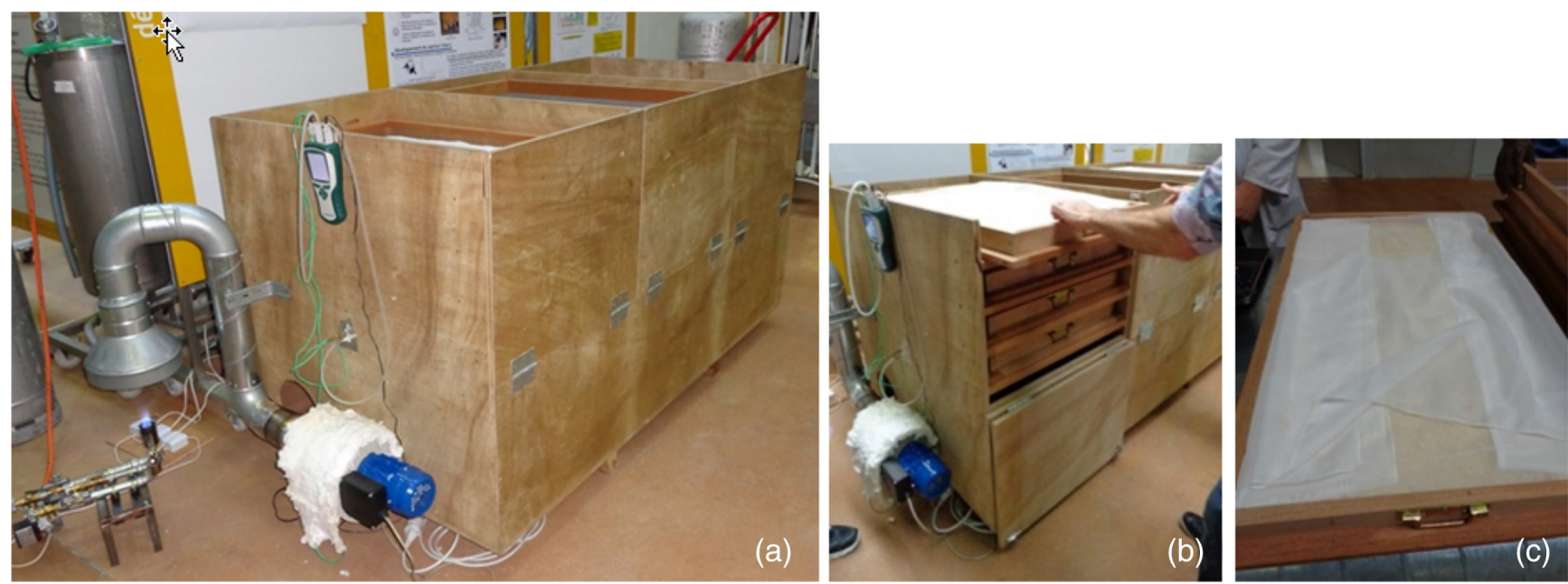

FIGURE 4 Pilot dryer (a) and dryer tray laden with product during trials ( $b$ and c)

which are defined or stipulated by the operating context. It is these input variables, which affect the behavior of the process.

\subsection{1 | Input variables: Design variables and context- related variables}

The design variables (Table 1) and context-related variables (Table 2) are those affecting the process sizing and behavior in a specific context of manufacture (locally made) and use in a developing country (West Africa). The choice of these design variables, as well as their variation domain (Table 1), was set and limited based on the expertise of the designers and users. Together, these domains define the process design solution search space.

The process of combining the biomass energy conversion with the dryer was designed for manufacture and use in developing countries. This specific context required the consideration of highly specific design variables, such as the dimensions of the tubes selected for manufacturing the heat exchanger. The selected diameters ( $d=42.4$, 60.3 , and $76.1 \mathrm{~mm}$ ) are those most commonly used in West Africa. Their length $\left(L_{\text {tube }}\right)$ provides a sufficient exchange surface area (>0.5 m), without exceeding $1.2 \mathrm{~m}$, so that the heat generator and heat exchanger can be associated in the same module. The lowest number of tubes $\left(N_{b}\right.$ tube $)$ is also determined by obtaining a minimum exchange surface area, and the highest number by estimating the

TABLE 1 List of the design variables

\begin{tabular}{|lll|}
\hline $\begin{array}{l}\text { Design variables } \\
\text { External tube diameter }(d)\end{array}$ & Unit & $\begin{array}{l}\text { Variation } \\
\text { domain }\end{array}$ \\
\hline $\begin{array}{l}\text { Tube length }\left(L_{\text {tube }}\right) \\
\text { Number of tubes }\left(N_{\mathrm{b}} \text { tube }\right)\end{array}$ & $\mathrm{mm}$ & $\begin{array}{c}42.4 ; 60.3 ; \\
76.1\}\end{array}$ \\
\hline $\begin{array}{l}\text { Bend angle of turbulator }(\alpha) \\
\text { Free sectional flow between turbulator } \\
\text { and tube }(\Delta S)\end{array}$ & m & {$[0.5 ; 1.2]$} \\
\hline $\begin{array}{l}\text { Hot flue gas temperature }\left(T_{\mathrm{ip}}\right) \\
\text { Radius of hot flue gas extractor impeller } \\
\left(R_{\mathrm{p}}\right)\end{array}$ & $\mathrm{m}$ & {$[3 ; 25]$} \\
\hline \begin{tabular}{l} 
Radius of fan impeller $\left(R_{\mathrm{s}}\right)$ \\
\hline
\end{tabular} & & {$[10 ; 50]$} \\
\hline
\end{tabular}

maximum allowable weight, to ensure that the heat exchanger is transportable and its price accessible.

Two variables characterize the elliptic turbulators and have a major impact on exchanger performance: $\alpha$, the ellipse bend angle, and $\Delta S$, the free sectional flow between turbulator and tube due to the manufacturing geometrical dispersions (Rivier et al., 2015). For an angle of less than $45^{\circ}$, it is very difficult to bend the sheet and the pressure drop is high. Above $60^{\circ}$, the heat transfer rate is excessively impaired. Measurements made on turbulators manufactured in developing countries showed that the geometric manufacturing tolerances to obtain a $\Delta S$ value of less than $10 \%$ are too strict and cannot be achieved with local manufacturing tools and techniques. Above 50\%, the heat transfer rate is excessively impaired.

The hot flue gas temperature range at the heat exchanger inlet takes into account the diversity of the biomass heat generators. Below $400{ }^{\circ} \mathrm{C}$, biomass combustion is considered poor, and above $800{ }^{\circ} \mathrm{C}$, the heat exchanger may be damaged (expansion, damage to welds, etc.).

The fan impeller radii domain values were selected for the ease of local manufacture and the ability to generate fluid flows in accordance with the requirements of the dryers defined by the experts.

The context-related variables were also set (Table 2) according to the production conditions in developing countries. Hence, the temperature $\left(T_{\text {is }}\right)$ and relative humidity of the ambient air $\left(\mathrm{HR}_{\mathrm{is}}\right)$ were set, respectively, at $25{ }^{\circ} \mathrm{C}$ and $50 \%$. The initial dry based moisture content $\left(W_{\mathrm{db} \_ \text {init }}\right)$ of the agglomerated product was $0.82 \mathrm{~kg} / \mathrm{kg}$. The angular

TABLE 2 List and value of the context-related variables

\begin{tabular}{lll}
\hline Context-related variables & Unit & Value \\
\hline Ambient air temperature $\left(T_{\text {is }}\right)$ & ${ }^{\circ} \mathrm{C}$ & 25 \\
\hline Ambient air relative humidity $\left(\mathrm{HR}_{\mathrm{is}}\right)$ & $\%$ & 50 \\
\hline Initial dry based moisture content $\left(\mathrm{W}_{\mathrm{db} \_ \text {init }}\right)$ & $\mathrm{kg} / \mathrm{kg}$ & 0.82 \\
\hline Fan angular velocity $(\omega)$ & $\mathrm{rad} / \mathrm{s}$ & 298.5 \\
\hline Columns number $\left(\mathrm{N}_{\mathrm{b} \text { col }}\right)$ & - & 3 \\
\hline Trays number per column $\left(N_{\mathrm{b} \text { tray }}\right)$ & - & 4 \\
\hline Product mass per tray $\left(\mathrm{M}_{\text {prod }}\right)$ & $\mathrm{kg}$ & 7 \\
\hline Tray area $\left(A_{\text {tray }}\right)$ & $\mathrm{m}^{2}$ & 0.45 \\
\hline
\end{tabular}


TABLE 3 List of the performance variables

\begin{tabular}{|c|c|c|}
\hline Design objectives & Performance variables & $\begin{array}{l}\text { Desirable } \\
\text { domain }\end{array}$ \\
\hline Product quality & $\begin{array}{l}\text { Drying air temperature } \\
\left(T_{\mathrm{os}}\right)\end{array}$ & $<60^{\circ} \mathrm{C}$ \\
\hline Non-fluidized bed & $\begin{array}{l}\text { Air velocity through } \\
\text { product }\left(U_{\text {prod }}\right)\end{array}$ & $<0.3 \mathrm{~m} / \mathrm{s}$ \\
\hline $\begin{array}{l}\text { Energy performance } \\
\text { (constraint) }\end{array}$ & $\begin{array}{l}\text { Primary circuit pressure } \\
\quad \text { drop }\left(\Delta P_{\mathrm{p}}\right)\end{array}$ & $<80$ pa \\
\hline $\begin{array}{l}\text { Energy performance } \\
\text { (constraint) }\end{array}$ & $\begin{array}{l}\text { Mechanical power of } \\
\text { secondary circuit fan } \\
\text { (MPw) }\end{array}$ & $<1 \mathrm{~kW}$ \\
\hline $\begin{array}{l}\text { Energy performance } \\
\quad \text { (functional) }\end{array}$ & Unit efficiency (Eff) & $>36 \%$ \\
\hline $\begin{array}{l}\text { Production performance } \\
\text { (functional) }\end{array}$ & Productivity (Prod) & $>20 \mathrm{~kg} / \mathrm{hr}$ \\
\hline $\begin{array}{l}\text { Non-fouling and } \\
\text { equipment service life }\end{array}$ & $\begin{array}{l}\text { Hot flue gas outlet } \\
\text { temperature }\left(T_{\mathrm{op}}\right)\end{array}$ & $>120^{\circ} \mathrm{C}$ \\
\hline Equipment service life & $\begin{array}{l}\text { Hot flue gas outlet } \\
\text { temperature }\left(T_{\mathrm{op}}\right)\end{array}$ & $<220^{\circ} \mathrm{C}$ \\
\hline $\begin{array}{l}\text { Local manufacture in } \\
\text { developing countries }\end{array}$ & $\begin{array}{l}\text { Exchanger steel mass } \\
\left(M_{\text {exch }}\right)\end{array}$ & $<50 \mathrm{~kg}$ \\
\hline
\end{tabular}

velocity $(\omega)$ of the electric motors fitted on the fans was $298.5 \mathrm{rad} / \mathrm{s}$ (2,850 rpm), which corresponds to the most commonly available motors in developing countries.

Preliminary validation tests have led to a dryer configuration with four stacked trays. Indeed, in steady state, the air becomes saturated or near-saturated at the outlet of the fourth tray. Also, the product in any additional trays would not dry, since it would encounter air saturated with water, and also provide conditions favorable for microbial development (molds and fermentation flora). The number of columns is determined by the desired production capacity. A three-column dryer configuration, suited to the characteristics of units in West Africa, was adopted for our study. The tray dimensions, length and width, were defined to aid handling and adhere to a standard format for the processors: $900 \mathrm{~mm} \times 600 \mathrm{~mm}$ (external dimensions), that is, an active surface area of approximately $0.45 \mathrm{~m}^{2}\left(A_{\text {tray }}\right)$. They weighed $3 \mathrm{~kg}$. According to French standard NF X 35-109 (2011), the carrying load limit for an operator is 10 or $12.5 \mathrm{~kg}$, depending on age. The wet product mass per tray $\left(M_{\text {prod }}\right)$ was therefore set at $7 \mathrm{~kg}$, that is, with a product layer thickness of $28 \mathrm{~mm}$.

\subsection{2 | Process performance variables}

These variables presented in detail in Table 3 are the process performance indicators. For each one, a desirable domain is specified.

The first two variables concern the food product itself. The drying air temperature $\left(T_{\mathrm{os}}\right)$ must not exceed $60{ }^{\circ} \mathrm{C}$, in order to prevent starch gelatinization and color alteration (browning). In addition, this type of agglomerated product must not be subjected to an air velocity $\left(U_{\text {prod }}\right)$ of more than $0.3 \mathrm{~m} / \mathrm{s}$. Above that, the product bed becomes fluidized, with preferential openings and air passages created in the layer.

The primary circuit pressure drop $\left(\Delta P_{p}\right)$ range led us to propose stack effect or forced convection technical solutions.

The mechanical power (MPw) required for the secondary circuit fan must be less than $1 \mathrm{~kW}$, in order to ensure power availability on the local power network, that is, a current of less than $6 \mathrm{~A}$ at a voltage of $220 \mathrm{~V}$.

The process efficiency (Eff) was evaluated at steady state for duration $\Delta t$, as the ratio between the energy required to evaporate the water in the product and the energy supplied. According to Boroze et al. (2014), the highest energy efficiency found on a direct gas combustion dryer in West Africa is $36 \%$. The minimum objective was to achieve this value for the process as a whole.

The dried product flow (Prod) must be at least $20 \mathrm{~kg} / \mathrm{hr}$, in order to match local production capacities.

To prevent a condensation phenomenon, the hot flue gas temperature at the primary circuit outlet $\left(T_{\mathrm{op}}\right)$ must be at least $120^{\circ} \mathrm{C}$. It must not exceed $220^{\circ} \mathrm{C}$, to avoid damaging the hot flue gas extractor.

For price and handling reasons, the mass of the heat exchanger $\left(M_{\text {exch }}\right)$ must not exceed $50 \mathrm{~kg}$.

\section{3 | Programming tool}

All of the models for the process as a whole were developed using the Matlab ${ }^{\circledR}$ R2012b software (MathWorks Inc., Natick, MA, USA).

\section{3 | RESULTS AND DISCUSSION}

This paragraph explains how the physical models associated with each unit operation were developed and then presents a combined model for the process as a whole. Finally, this combined model was used to evaluate the design solution performances.

\section{1 | Tubular heat exchanger modelling}

The intensity of heat transfer between the two circuits, primary and secondary, is dependent on (1) the air flows generated respectively by the hot flue gas extractor and the drying air fan and (2) the configuration of the circuits. A circuit duty point was sought for each of these two circuits.

Based on the information supplied by a fan manufacturer ("Sodeca" Co., Barcelona, Spain), for each fan, a polynomial regression model linking the allowable pressure drop $\Delta P$ as a function of the fluid volume flow rate $\dot{V}$ to the design variables, radius $R$, and wheel angular velocity $\omega$ are expressed as follows:

$$
\begin{gathered}
\Psi=a \cdot \varphi^{3}+b \cdot \varphi^{2}+c \cdot \varphi+d \\
\text { where } \\
\Psi=\frac{\Delta P}{\rho \cdot \omega^{2} \cdot R^{2}} \text { and } \varphi=\frac{\dot{V}}{\omega \cdot R^{3}}
\end{gathered}
$$

Hence, both the fan performance curves were obtained for values of the variables $R$ and $\omega$ specific to each of the two fans; $a, b, c$, and

TABLE 4 Numerical parameters of hot flue gas extractor performance curve

\begin{tabular}{cllll} 
& $\boldsymbol{a}_{\mathbf{p}}$ & $\boldsymbol{b}_{\mathbf{p}}$ & $\boldsymbol{c}_{\mathbf{p}}$ & $\boldsymbol{d}_{\mathbf{p}}$ \\
$\begin{array}{c}\text { Hot flue gas } \\
\text { extractor }\end{array}$ & $-8.75 .10^{-2}$ & $1.34 .10^{-1}$ & $-1.49 .10^{-1}$ & $9.05 .10^{-1}$ \\
\hline
\end{tabular}


TABLE 5 Numerical parameters of drying air fan performance curve

$\begin{array}{lllll} & a_{\mathbf{s}} & b_{\mathbf{s}} & c_{\mathbf{s}} & d_{\mathbf{s}} \\ \text { Drying air fan } & -5.40 .10^{-3} & -4.78 .10^{-2} & -1.99 .10^{-1} & 1.61\end{array}$

$d$ (Tables 4 and 5) being the numerical parameters of the curve correlations, specific for each of the two fan models (hot flue gas extractor and drying air fan).

\subsection{1 | Pressure drops and heat transfer models in primary circuit}

In addition to conventional performance factors of heat exchangers (heat transfer and flow friction) (Webb, 1981, 2005), the design of a turbulator for developing countries must take into account the host of highly specific constraints. These relate to local availability of materials, local techniques, and manufacturing tooling. Hence, Rivier et al. (2015) characterized the original turbulator profile, based on an elliptical shape, and produced models for heat transfer (Nusselt number) and energy dissipation (friction factor) on this circuit.

The energy dissipation induced by installing elliptic shaped turbulators in the heat exchanger tubes was calculated from the previous model (Rivier et al., 2015); then, the pressure drop was calculated using the Darcy-Weisbach equation. Ultimately, the value of this pressure drop on the primary circuit is dependent on the hot flue gas volume flow rate and the following design variables: tube diameter $d_{\text {int }}$, tube length $L_{\text {tube, }}$, number of tubes $N_{\mathrm{b}}$ tube, ellipse turbulator bend angle $\alpha$, and the percentage $\Delta S$.

Hence, according to the design variables (hot flue gas extractor and turbulator) specific to each design solution, the primary circuit duty point, the intersection between the hot flue gas extractor performance curve, and the primary circuit energy dissipation curv can be calculated. An example is presented in Figure 5:

The Nusselt number, $\mathrm{Nu}_{\mathrm{p}}$, is calculated from the previous model (Rivier et al., 2015). Then, the internal heat transfer coefficient $h_{\text {int }}$ was determined:

$$
h_{\text {int }}=\frac{N u_{p} \cdot \lambda_{\text {ip }}}{d_{\text {int }}}
$$

$\lambda_{\text {ip }}$ is the thermal conductivity.

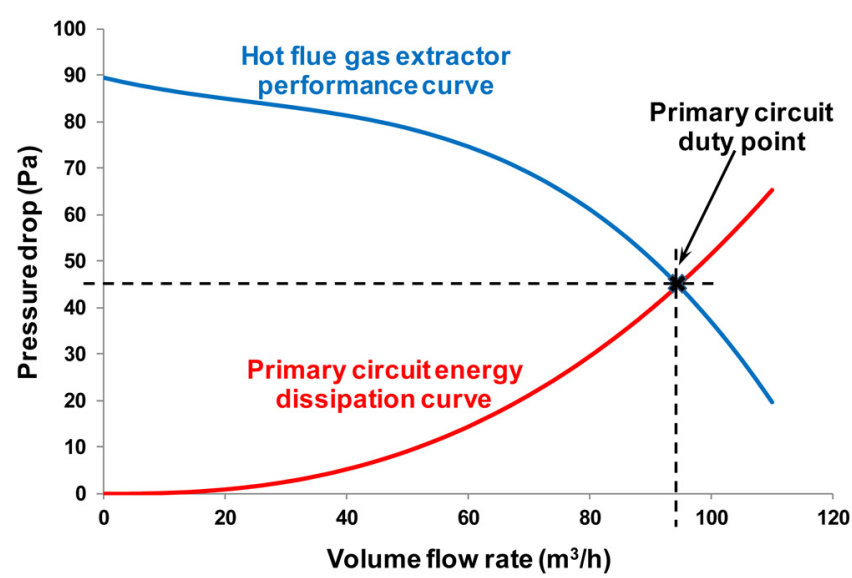

FIGURE 5 Determining the primary circuit duty point

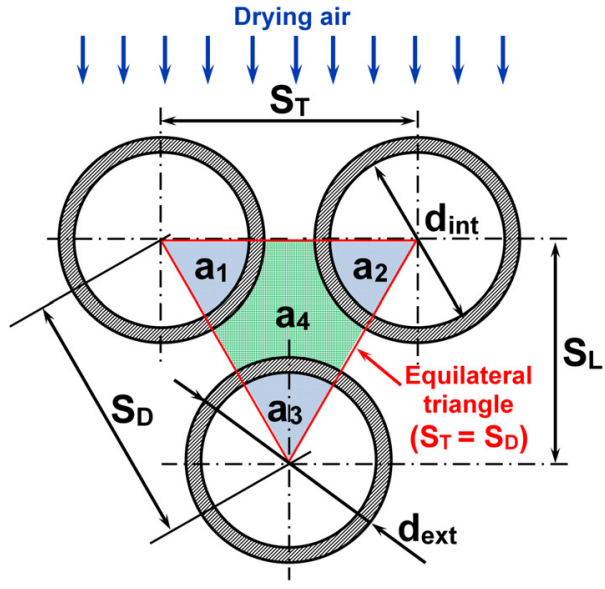

FIGURE 6 Heat exchanger tube bundle arrangement

\subsection{2 | Pressure drops and heat transfer models in secondary circuit}

The energy dissipation is associated with flow across the tube bundle of the heat exchanger and the food product positioned on the dryer trays.

The selected geometric configuration (Figure 6) for the heat exchanger was a staggered tube bundle arrangement in the form of an equilateral triangle.

According to a manufacturing rule conventionally used in heat exchanger design, surface areas $a_{1}, a_{2}, a_{3}$, and $a_{4}$ are linked by Equation (3) such that the sum of the hot flue gas passage surface areas $a_{1}$, $a_{2}$, and $a_{3}$ is the same as the drying air passage surface area $a_{4}$.

$$
a_{4}=a_{1}+a_{2}+a_{3}
$$

This equality led to the following equation defining $S_{\mathrm{T}}$ :

$$
S_{T}=S_{D}=\sqrt{\frac{\pi \cdot\left(d_{\text {ext }}^{2}+d_{\text {int }}^{2}\right)}{2 \cdot \sqrt{3}}}
$$

According to the literature (Bergman, Incropera, \& Lavine, 2011), the pressure drop $\Delta P_{\text {bundle }}$ generated by the air flow (of density $\rho_{\mathrm{s}}$ ) across the tube bundle ( $N_{L}$ rows of tubes) is expressed as follows:

$$
\Delta P_{\text {bundle }}=N_{\mathrm{L}} \cdot\left(\frac{\rho_{\mathrm{s}} \cdot U_{\max }^{2}}{2}\right) \cdot f_{\mathrm{s}}
$$

with

$$
U_{\max }=\frac{S_{\mathrm{T}}}{S_{\mathrm{T}}-d_{\mathrm{ext}}} \cdot U
$$

$U_{\max }$ is the maximum velocity occurring within the tube bundle, $U$ is the mean velocity at the heat exchanger pass inlet section, and $f_{\mathrm{s}}$ is the friction factor.

According to Bergman et al. (2011), the friction factor values $f_{\mathrm{s}}$ are expressed as a function of the Reynolds number $\left(\operatorname{Re}_{\max }\right)$. The curve corresponding to the ratio $S_{\mathrm{T}} / d_{\text {ext }}$ of our configuration was digitized and expressed as follows:

$$
\begin{gathered}
\log f_{s}=0.12 \cdot x^{3}-2.11 \cdot x^{2}+14.39 \cdot x+85.62 \cdot x^{-1}-68.94 \cdot x^{-2} \\
+21.46 \cdot x^{-3}-49.12 \\
\text { where } \\
x=\log \operatorname{Re}_{\max }
\end{gathered}
$$




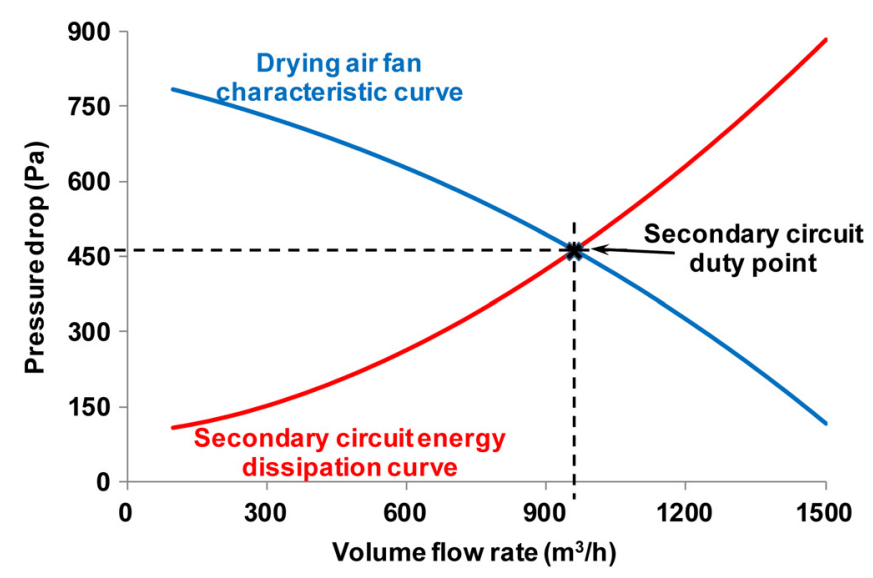

FIGURE 7 Determining the secondary circuit duty point

For the total pressure drop calculation, the value calculated in Equation (5) was multiplied by two, to take into account the two exchanger passes (see Figure 2).

The pressure drop across the food product layer depends on the air flow, following Equation (8) calculated experimentally:

$$
\Delta P_{\text {layer }}=2.29 \cdot 10^{-4} \cdot\left(\frac{\dot{V}_{\text {is }}}{3}\right)^{2}+1.37 \cdot 10^{-1} \cdot\left(\frac{\dot{V}_{\text {is }}}{3}\right)-3.4
$$

where $\dot{V}_{\text {is }}$ is the total secondary circuit volume flow rate.

Experience tells us that this is constant over time. During drying, the increase in pressure drop is offset by the settling of the product bed.

Hence, according to the design variables (drying air fan and tube bundle) specific to each design solution, the secondary circuit duty point, the intersection between the drying air fan performance curve, and the secondary circuit energy dissipation curve can be calculated. An example is presented in Figure 7:

Hence, the $\mathrm{Re}_{\max }$ was determined based on the drying air volume flow rate and then the Nusselt number $\mathrm{Nu}_{\mathrm{s}}$ as a correlation from the literature (Bergman et al., 2011):

$$
\mathrm{Nu}_{\mathrm{s}}=C_{1} \cdot \operatorname{Re}_{\max }{ }^{m} \cdot \operatorname{Pr}^{0.36} \cdot C_{2}
$$

Parameters $C_{1}$ and $m$ depend on the maximum Reynolds number $\mathrm{Re}_{\text {max }}$ as per Table 6.

The coefficient $C_{2}$ depends on the number of rows of tubes $N_{\mathrm{L}}$. It is equal to 1 if $N_{\mathrm{L}}$ is equal to or greater than 20. Otherwise, we use Equation (10) put together from the data from Bergman et al. (2011):

$$
C_{2}=1-\frac{1.02 \cdot 10^{-3}}{N_{\mathrm{L}}}-\frac{3.85}{N_{\mathrm{L}}^{2}}+\frac{11.1}{N_{\mathrm{L}}^{3}}-\frac{13.75}{N_{\mathrm{L}}^{4}}+\frac{6.14}{N_{\mathrm{L}}^{5}}
$$

Then, the external heat transfer coefficient $h_{\text {ext }}$ was expressed as follows:

$$
h_{\mathrm{ext}}=\frac{\mathrm{Nu}_{\mathrm{s}} \cdot \lambda_{\mathrm{is}}}{d_{\mathrm{ext}}}
$$

\subsection{3 | Global heat transfer between primary and secondary circuits}

The global heat transfer coefficient $h_{\text {glob}}$, the heat capacity ratio $R_{c}$, the number of transfer units NUT, the effectiveness $\varepsilon$, the hot flue gas outlet temperature $T_{\mathrm{op}}$, and air drying temperature $T_{\mathrm{os}}$ were calculated as follows:

$$
\begin{gathered}
h_{\text {glob }}=\frac{1}{\left(\pi \cdot d_{\text {med }} \cdot L_{\text {tube }}\right) \cdot\left(\frac{1}{\pi \cdot d_{\text {int }} \cdot L_{\text {tube }} \cdot h_{\text {int }}}+\frac{\ln \left(d_{\text {ext }} / d_{\text {int }}\right)}{2 \pi \cdot L_{\text {tube }} \cdot \text { iron }_{\text {ing }}}+\frac{1}{\pi \cdot d_{\text {ext }} \cdot L_{\text {tube }} \cdot h_{\text {ext }}}\right)} \\
R_{c}=\frac{\dot{m}_{\mathrm{p}} \cdot C_{\mathrm{pp}}}{\dot{m}_{\mathrm{s}} \cdot C_{\mathrm{ps}}} \\
\text { NUT }=\frac{h_{\text {glob }} \cdot 4 \cdot L_{\text {tube }}}{U_{\text {tube }} \cdot d_{\text {int }} \cdot \rho_{\text {ip }} \cdot C_{\mathrm{pp}}}
\end{gathered}
$$

where $U_{\text {tube }}=\frac{\dot{m}_{\mathrm{p}}}{N_{\mathrm{b} \text { tube }} \cdot \frac{\pi \cdot d^{2} \text { int }}{4} \cdot \rho_{\text {ip }}}$

$$
\begin{gathered}
\varepsilon=\frac{e^{\left(1-R_{\mathrm{c}}\right) \cdot \mathrm{NUT}}-1}{e^{\left(1-R_{\mathrm{c}}\right) \cdot \mathrm{NUT}}-R_{\mathrm{c}}} \\
T_{\mathrm{op}}=T_{\text {ip }}-\varepsilon \cdot\left(T_{\text {ip }}-T_{\text {is }}\right) \\
T_{\text {os }}=T_{\text {is }}+\left[R_{\mathrm{c}} \cdot \varepsilon \cdot\left(T_{\text {ip }}-T_{\text {is }}\right)\right]
\end{gathered}
$$

\section{2 | Packed bed dryer modelling}

A simple physical model of heat and mass transfer for agglomerated products drying was developed specially for this study.

The cereal based products to be dried possess a highly marked open porosity (Hafsa et al., 2014). They are agglomerated flour particles with a diameter of around $125 \mu \mathrm{m}$. Hence, for low drying air

TABLE 6 Numerical parameters for external Nusselt number calculation

\begin{tabular}{lll}
$\operatorname{Re}_{\max }$ & $C_{1}$ & $m$ \\
$10-10^{2}$ & 0.90 & 0.40 \\
$10^{2}-10^{3}$ & 1.15 & 0.50 \\
$10^{3}-2.10^{5}$ & $0.35\left(S_{T} / S_{L}\right)^{1 / 5}$ & 0.60 \\
$2.10^{5}-2.10^{6}$ & 0.022 & 0.84 \\
\hline
\end{tabular}


velocity $(<0.3 \mathrm{~m} / \mathrm{s})$, which is the case for our study, we expressed the hypothesis that internal water transport within the agglomerates was not limiting throughout drying. Under these circumstances, it was the external transfer conditions, which determined the drying kinetics. Drying was considered as isenthalpic. The product warm-up phase (very short) and sensible heat (4\% of the total energy involved) were neglected. Equation (18) describes the heat transfer between the air and the agglomerates in a couscous layer of thickness $e_{\text {prod. }}$.

$$
\frac{d Q}{d t}=h \cdot S_{\text {se }} \cdot e_{\text {prod }} \cdot A_{\text {tray }} \cdot\left(T_{\mathrm{a}}-T_{\text {ah }}\right)
$$

where $h$ is the convective heat transfer coefficient, $S_{\mathrm{se}}$ is the specific exchange surface area, $e_{\text {prod }}$ is the product layer thickness, $A_{\text {tray }}$ is the tray area, $T_{\mathrm{a}}$ is the dry air temperature, and $T_{\mathrm{ah}}$ is the wet bulb temperature.

The only remaining unknown was $h \cdot S_{\text {se }}$, which was identified experimentally on the pilot dryer (Figure 4).

Hence, we deduced the evaporation water flow:

$$
\frac{d M_{\mathrm{w}}}{d t}=\frac{d Q / d t}{L_{e v}}
$$

$L_{\mathrm{ev}}$ is the latent heat of water evaporation.

The rate of drying was expressed as follows:

$$
\frac{d W_{\mathrm{db}}}{d t}=\frac{1}{e_{\text {prod }} \cdot A_{\text {tray }} \cdot \frac{\rho_{\text {prod }}}{W_{\text {db init }}+1}} \cdot \frac{d M_{\mathrm{w}}}{d t}
$$

$\rho_{\text {prod }}$ is the initial wet matter bulk density of agglomerated product and $W_{\mathrm{db} \text { init }}$ is the initial dry basis moisture content of agglomerated product.

Figure 8 presents the experimental drying kinetics, and those derived from the four stacked trays model, under conventional drying conditions for this type of product. We can observe a good match between the experimental and predicted values (difference less than $5 \%$ ).

In addition, it was verified that the drier reaches steady state from tray 3 . Hence, the time measured between removing tray 3 and tray 4 corresponds to the removal frequency of the following trays. These various points were factored into the simulation tool.

\section{3 | Developing the model combining the tubular heat exchanger and the packed bed dryer}

A numerical simulation tool for the process as a whole was developed, using the functional algorithm presented in Figure 9.

It comprises two main structural parts. The first relates to the exchanger and defines its geometric configuration, the duty point for each circuit, primary and secondary, and the heat exchanger performance indicators. The second part concerns the dryer and calculates the evolution of product water loss over time.

In terms of the exchanger, the first step consists in initializing the values of the eight design variables (Table 1). Similarly, the hot flue gas temperature value at the primary circuit outlet $\left(T_{o p}\right)$ had to be attributed in order to determine the duty point of the primary circuit. A new value of $T_{\text {op }}$ was obtained after global heat transfer simulation. An iterative calculation, using a relaxation method, was used to ensure convergence toward the final value of $T_{\mathrm{op}}$. Thus, properties, such as $\dot{m}_{\mathrm{s}}, T_{\mathrm{os}}$, and $\mathrm{HR}_{\mathrm{os}}$, of the air from the secondary circuit, are produced and correspond to the initial conditions of the drying air.

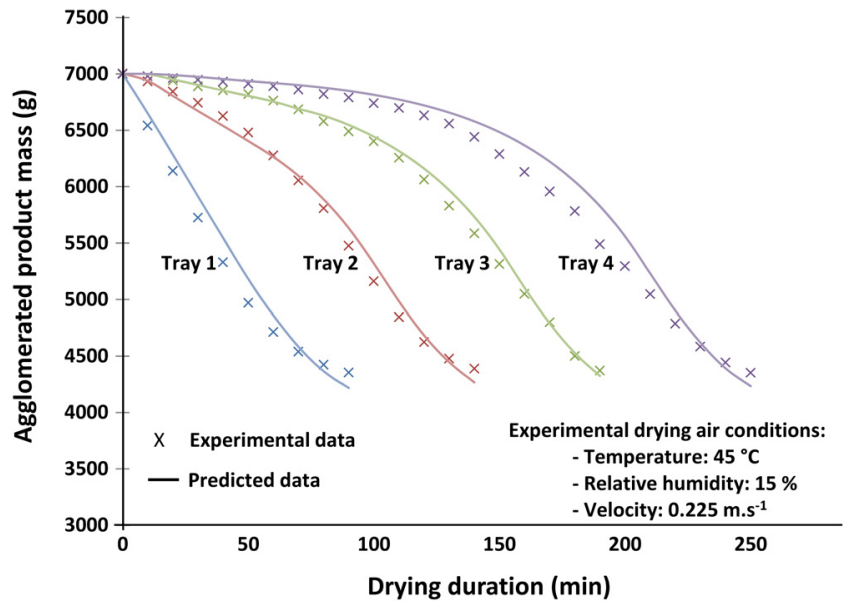

FIGURE 8 Experimental and predicted data of a drying cycle on the pilot dryer

To calculate the drying part (a time-dependent phase), the product layer is broken down into an array of nblayers elementary layers of thickness $e_{\text {prod. }}$. At $t=0$, for a duration $d t$, the initial conditions of the drying air are applied at the inlet of the first elementary layer of the product, with initial water content $W_{\mathrm{db} \text { init }}(0.82 \mathrm{~kg} / \mathrm{kg})$. So, the heat and mass transfer drying model is able to calculate (1) the new water content of the elementary layer product after the drying air pass and (2) the new drying air properties upon exiting this layer. The evaporating capacity of the air is evaluated in order to verify whether it is in a condition fit to dry the following layers. If this is the case, this air is used until the total number of layers is reached. If the air is saturated or if all the elementary product layers have been treated, the product water content in the final layer is evaluated. If it is greater than the target water content (i.e., $0.11 \mathrm{~kg} / \mathrm{kg}$ for stability purposes), drying is continued and a new calculation cycle is engaged at $t+d t$. If the final product layer is dry, the drying simulation is interrupted.

For each time step $d t$, the water content values of all the elementary layers are stored in a matrix. Postprocessing of these values is used in order to assess the process performances via the production of performance variables values. A time convergence $(d t)$ and space convergence $\left(e_{\text {prod }}\right)$ study was conducted on the water content values. Time values $d t 1 \mathrm{~s}$ and mesh values $1 \mathrm{~mm}$ were deemed optimal in terms of simulation tool precision and calculation time.

Hence, a simulation model for the entire process is available. This combined model was built based on experimental models, developed either by this study (dryer modeling) or by a previous study (Rivier et al., 2015) combined with models derived from the literature (Bergman et al., 2011). The values of the performance variables derived from this combined model were compared against numerous experimental results (see Figure 8). They demonstrated its perfect prediction capacity, making it a high-performance process design aid tool.

\subsection{Using the combined model to evaluate equipment design solutions}

\subsection{1 | Choice of the design solutions tested}

The choice of the six design solutions had to shed some light on the performance of the biomass energy exchanger for drying cereal-based 


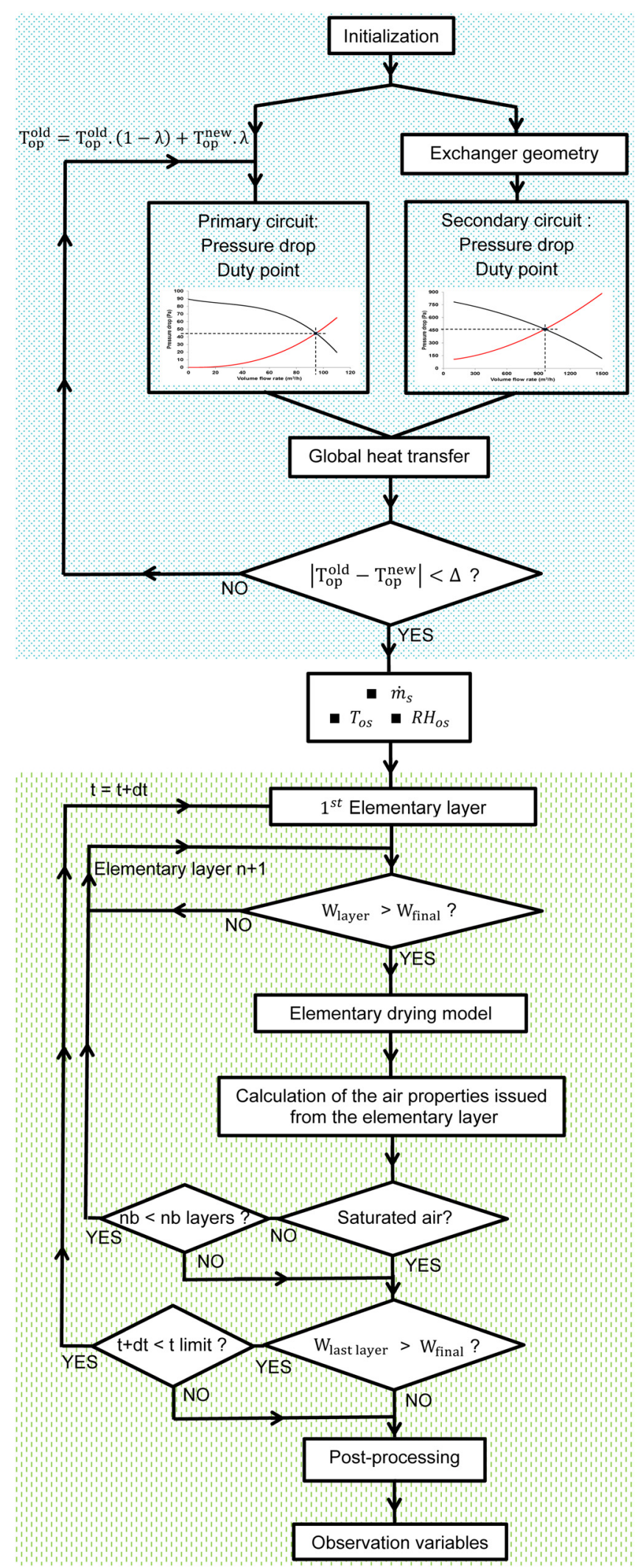

FIGURE 9 Process simulation running algorithm

products. Hence, the combined model was designed so that the design could be assessed, whether or not the turbulators were present in the exchanger. The exchanger's capacities are characterized by heat transfer (Nusselt number) and pressure drop (friction factor). Table 7 presents six design solutions to be assessed in terms of performance.
For each one, the diameter $(d)$, length $\left(L_{\text {tube }}\right)$, and number of tubes $\left(N_{\mathrm{b}}\right.$ tube) are set, respectively, at $60.3 \mathrm{~mm}, 0.7 \mathrm{~m}$ and 8 tubes. The hot flue gas temperature at the primary circuit inlet $\left(T_{\mathrm{ip}}\right)$ is set at $640{ }^{\circ} \mathrm{C}$, and the radius of the fan impeller $\left(R_{\mathrm{s}}\right)$ is set at $75 \mathrm{~mm}$. In solution $\mathrm{S} 1$, the tubes are not equipped with a turbulator; a "wire coil turbulator" 
TABLE 7 Presentation of the various solutions tested

\begin{tabular}{|c|c|c|c|c|c|c|}
\hline Design variables & $\begin{array}{l}\text { S1 } \\
\text { Plain tube }\end{array}$ & $\begin{array}{l}\text { S2 } \\
\text { Wire coil }\end{array}$ & $\begin{array}{l}\text { S3 } \\
\text { Elliptic }\end{array}$ & $\begin{array}{l}\text { S4 } \\
\text { Elliptic }\end{array}$ & $\begin{array}{l}\text { S5 } \\
\text { Elliptic }\end{array}$ & $\begin{array}{l}\text { S6 } \\
\text { Elliptic }\end{array}$ \\
\hline$d(\mathrm{~mm})$ & 60.3 & 60.3 & 60.3 & 60.3 & 60.3 & 60.3 \\
\hline$L_{\text {tube }}(m)$ & 0.7 & 0.7 & 0.7 & 0.7 & 0.7 & 0.7 \\
\hline$N_{\mathrm{b} \text { tube }}$ & 8 & 8 & 8 & 8 & 8 & 8 \\
\hline$\alpha\left(^{\circ}\right)$ & - & - & 45 & 45 & 45 & 60 \\
\hline$\Delta S(\%)$ & - & - & 10 & 30 & 50 & 15 \\
\hline$R_{\mathrm{p}}(\mathrm{m})$ & 0.0425 & 0.0425 & 0.0365 & 0.0365 & 0.0365 & 0.0365 \\
\hline$R_{\mathrm{s}}(\mathrm{m})$ & 0.075 & 0.075 & 0.075 & 0.075 & 0.075 & 0.075 \\
\hline
\end{tabular}

profile (Eiamsa-Ard, Kongkaitpaiboon, \& Promvonge, 2011) was chosen for solution S2, while solutions S3-S6 use different elliptic turbulator variants (by angle $[\alpha]$ and free sectional flow between turbulator and tube $[\Delta S])$. The radius of the hot flue gas extractor impeller $\left(R_{\mathrm{p}}\right)$ is defined so that the six solutions are compared based on the same power supplied by the generator.

\subsubsection{Performances of the design solutions tested}

Table 8 presents the results provided by the combined model in terms of performance variables of the design solutions tested.

Table 8 shows that, for the design solutions proposed, the values obtained for each of the observation variables follow an easily understandable pattern, which agrees with experience. Hence, we can observe that for an exchanger built with the same diameter $(d=60.3 \mathrm{~mm})$, length $\left(L_{\text {tube }}=0.7 \mathrm{~m}\right)$, and number of tubes $\left(N_{\mathrm{b}}\right.$ tube $=$ 8 ), the contribution of elliptical turbulators (solution S3) favorably affects the expected performances in terms of heat transfer (values of performance variables $T_{\text {os }}$, Eff, Prod, $T_{\text {op }}$ ) but causes a big increase in the pressure drop $\left(\Delta P_{p}\right)$ in the primary circuit. Conversely, solutions $\mathrm{S} 4, \mathrm{~S} 5$, and S6 show that the increased percentage sectional flow $(\Delta \mathrm{S})$ considerably reduces $\Delta P_{\mathrm{p}}$ without proportionally affecting the heat transfer. For the six design solutions, the drying air speed values $\left(U_{\text {prod }}\right)$ are very similar (as for the fan mechanical power [MPw]), due to the configuration of the secondary circuit having been set (same fan and tube bundle). The slight variation in $U_{\text {prod }}$ can readily be explained by the variation in air density as a function of the drying temperature $\left(T_{\text {os }}\right)$.

These drying air temperatures $\left(T_{o s}\right)$ are significantly different. While in every case the values comply with the chosen desirability domain $\left(T_{\text {os }}<60^{\circ} \mathrm{C}\right.$ ) and the integrity of the food product, the presence of a turbulator has a remarkable effect on these values: from $38{ }^{\circ} \mathrm{C}$ (solution S1 without a turbulator) to nearly $60{ }^{\circ} \mathrm{C}$ with an elliptical turbulator (solutions S3-S6). This observation of course agrees with the one stated above (effect of elliptical turbulators on heat transfer): the lower the values of $\alpha$ and $\Delta S$, the higher the drying temperature $\left(T_{\mathrm{os}}\right)$. The same goes for the evolution of production capacity (Prod) and energy efficiency (Eff), which change significantly, from $11 \mathrm{~kg} / \mathrm{hr}$ and $21.4 \%$, respectively (solution S1 without turbulator) to more than $22 \mathrm{~kg} / \mathrm{hr}$ and $46.8 \%$ (solution S3).

In conclusion, the values adopted by the performance indicators in the six design solutions signify good consistency of the combined process model with regard to the design team's expertise.

We will now analyze the relevance of the six adopted design solutions.

The readings (Table 8) for solution S1 confirm the poor performances of the process without the contribution of turbulators in the exchanger tubes: a small pressure $\operatorname{drop}\left(\Delta P_{\mathrm{p}}\right)$ but poor energy efficiency (Eff) and production capacity (Prod). For solution S2 (wire coil turbulator), the performances Eff and Prod are better, but at the expense of the pressure drop value $\left(\Delta P_{p}\right)$. For both these solutions, bringing the performances up to standard would involve significantly increasing the number of tubes, the volume and the exchanger mass $\left(M_{\text {ech }}\right)$. Our analysis will give no further consideration to these solutions.

Solutions S3-S6 show that elliptical turbulators intensify heat transfer and are able to achieve high value levels. The production capacity value (Prod) is within the target desirability domain (see Table 3 section 2.2.2), i.e., around $22 \mathrm{~kg} / \mathrm{hr}$. The energy efficiency (Eff) is between 43 and $47 \%$ inclusive, which is considerably higher than the values found in the field (maximum of around $23 \%$ according to Boroze et al., 2014). These performances are set out in Table 8.

TABLE 8 Performance variables values for each design solution tested

\begin{tabular}{|c|c|c|c|c|c|c|}
\hline Performance variables & $\begin{array}{l}\text { S1 } \\
\text { Plain tube }\end{array}$ & $\begin{array}{l}\text { S2 } \\
\text { Wire coil }\end{array}$ & $\begin{array}{l}\text { S3 } \\
\text { Elliptic }\end{array}$ & $\begin{array}{l}\text { S4 } \\
\text { Elliptic }\end{array}$ & $\begin{array}{l}\text { S5 } \\
\text { Elliptic }\end{array}$ & $\begin{array}{l}\text { S6 } \\
\text { Elliptic }\end{array}$ \\
\hline$T_{\text {os }}\left({ }^{\circ} \mathrm{C}\right)$ & 38.0 & 44.2 & 59.9 & 59.5 & 58.3 & 58.5 \\
\hline$U_{\text {prod }}(\mathrm{m} / \mathrm{s})$ & 0.210 & 0.215 & 0.225 & 0.225 & 0.224 & 0.224 \\
\hline$\Delta P_{\mathrm{p}}(\mathrm{Pa})$ & 11 & 61 & 41 & 11 & 6 & 12 \\
\hline $\mathrm{MPw}(\mathrm{W})$ & 805 & 805 & 805 & 805 & 805 & 805 \\
\hline Eff (\%) & 21.4 & 29.2 & 46.8 & 44.5 & 42.2 & 43 \\
\hline$T_{\text {op }}\left({ }^{\circ} \mathrm{C}\right)$ & 478 & 384 & 165 & 188 & 216 & 209 \\
\hline$M_{\text {exch }}(\mathrm{kg})$ & 28.5 & 30.9 & 32.4 & 32.0 & 31.6 & 31.7 \\
\hline
\end{tabular}


We can observe that for the elliptical turbulator solutions (S3, S4, and S5), where the bend $\alpha=45^{\circ}$, the increase in $\Delta S$ greatly limits the pressure drop $\left(\Delta P_{\mathrm{p}}\right)$ in the primary circuit (from 41 to $6 \mathrm{~Pa}$ ), without proportionally affecting the heat transfer: the other indicators Eff, Prod, $T_{\mathrm{op}}$, and $M_{\text {exch }}$ see little change. We can also note that with an elliptical turbulator where the bend $\alpha=60^{\circ}$ and $\Delta S=15 \%$ (solution S6), the performance indicators $\Delta P_{\mathrm{p}}$, Eff, Prod, $T_{\mathrm{op}}$, and $M_{\text {exch }}$ remain roughly the same as for solutions $S 4\left(\alpha=45^{\circ}\right.$ and $\left.\Delta S=30 \%\right)$ and S5 ( $\alpha=45^{\circ}$ and $\Delta S=50 \%$ ). In addition, in the knowledge that shaping an elliptical turbulator is much easier with $60^{\circ}$ than $45^{\circ}$, these findings are interesting, since the geometric manufacture tolerances of a turbulator could therefore be less strict, thereby favoring the manufacturing capacities in developing countries.

The low pressure drop values $\left(\Delta P_{\mathrm{p}}<20 \mathrm{~Pa}\right)$ observed in solutions S4, S5, and S6 are interesting, since stack effect hot flue gas extraction becomes viable. For the latter three solutions, as well as for solution S3, the hot flue gas temperature levels at the primary circuit outlet $\left(T_{\mathrm{op}}\right)$ remain low (from 165 to $216^{\circ} \mathrm{C}$ ), enabling local manufacture of an extractor.

Hence, the performance analysis on these design solutions provides highly relevant information in terms of the future control and sizing of the process. In particular, it demonstrates that the process predefinition phase is not to be neglected, since it requires in particular a compromise to be sought between contradictory criteria. For example, good thermal efficiency leads to a high pressure drop and requires the installation of a fan, whereas natural convection is more suitable in terms of favoring local manufacture and use. In addition, the number of variables and the extent of their variation domain make the quest for a high-performance solution a complex matter. Hence, this numerical tool is particularly well suited to the implementation of an optimization strategy for the design of a process combining a cereal dryer with a bioenergy unit.

\section{4 | CONCLUSION}

This study presents the development of a numerical simulator of a process combining a cereal dryer with a bioenergy unit. It is built on pressure drop models, as well as mass and heat transfer models, developed from experimental set-ups. Process performance indicators were defined and used to study six design solutions. The analysis of these six design solutions tested generated relevant information for developing the process for use in developing countries. Insofar as the thermal energy is produced by a high-performance generator, coupling a heat exchanger equipped with elliptic turbulators to a dryer could achieve high satisfaction levels in terms of the stated objectives.

In seeking a compromise between contradictory criteria, and due to the complexity of the design solutions search space, it appears desirable in the future to implement a genuine process optimization strategy, in order to automate the search for better alternatives according to the specified preferences. Methods using stochastic metaheuristics (e.g., a genetic algorithm) would seem particularly suitable. Hence, the definitive objective of this work will be to provide the process designer with a decision-making aid tool for researching high-performance design solutions.

\section{NOMENCLATURE}

\begin{tabular}{|c|c|}
\hline$A_{\text {tray }}$ & tray area $\left(\mathrm{m}^{2}\right)$ \\
\hline$C_{p}$ & heat capacity $\left(\mathrm{J} / \mathrm{kg} /{ }^{\circ} \mathrm{C}^{\prime}\right.$ \\
\hline$d$ & tube diameter $(\mathrm{mm})$ \\
\hline Eff & unit efficiency (\%) \\
\hline$e_{\text {prod }}$ & product layer thickness (m) \\
\hline$f$ & Friction factor \\
\hline$H R$ & air relative humidity (\%) \\
\hline$h$ & heat transfer coefficient $\left(\mathrm{W} / \mathrm{m}^{2} /{ }^{\circ} \mathrm{C}\right)$ \\
\hline$L_{\mathrm{ev}}$ & latent heat of water evaporation $(\mathrm{J} / \mathrm{kg})$ \\
\hline$L_{\text {tube }}$ & tube length (m) \\
\hline M & mass (kg) \\
\hline$M_{\text {exch }}$ & exchanger steel mass (kg) \\
\hline MPw & mechanical power (secondary circuit fan; kW) \\
\hline$\dot{m}$ & mass flow rate $(\mathrm{kg} / \mathrm{s})$ \\
\hline$N_{b}$ col & column number \\
\hline$N_{b}$ tray & tray number \\
\hline$N_{\mathrm{b}}$ tube & tube number \\
\hline$N_{\mathrm{L}}$ & tubes rows number \\
\hline $\mathrm{Nu}$ & Nusselt number \\
\hline NTU & number of transfer units \\
\hline $\operatorname{Pr}$ & Prandtl number \\
\hline Prod & productivity (kg/hr) \\
\hline$R$ & fan impeller radius $(m)$ \\
\hline$R_{\mathrm{c}}$ & heat capacity ratio \\
\hline $\operatorname{Re}$ & Reynolds number \\
\hline$S_{\mathrm{es}}$ & specific exchange surface $\left(\mathrm{m}^{2} / \mathrm{m}^{3}\right)$ \\
\hline$S_{\mathrm{D}}$ & diagonal pitch (m) \\
\hline$S_{\mathrm{T}}$ & transverse pitch (m) \\
\hline$T$ & temperature $\left({ }^{\circ} \mathrm{C}\right)$ \\
\hline$T_{a}$ & dry air temperature $\left({ }^{\circ} \mathrm{C}\right)$ \\
\hline$T_{\mathrm{ah}}$ & wet bulb temperature $\left({ }^{\circ} \mathrm{C}\right)$ \\
\hline$U$ & mean axial velocity $(\mathrm{m} / \mathrm{s})$ \\
\hline$\dot{V}$ & volume flow rate $\left(\mathrm{m}^{3} / \mathrm{s}\right)$ \\
\hline$W_{\mathrm{db}}$ & dry basis moisture content ( $\mathrm{kg}$ of water/kg of dry matter) \\
\hline$\Delta P$ & pressure drop $(\mathrm{Pa})$ \\
\hline$\Delta S$ & percentage sectional flow area left free by the turbulator \\
\hline
\end{tabular}

\section{GREEK SYMBOLS}

\author{
$\alpha$ bending angle (degree) \\ $\varepsilon$ effectiveness \\ $\lambda$ thermal conductivity $\left(\mathrm{W} / \mathrm{m} /{ }^{\circ} \mathrm{C}\right)$ \\ $\rho$ density $\left(\mathrm{kg} / \mathrm{m}^{3}\right)$ \\ $\varphi$ flow rate coefficient \\ $\psi$ pressure coefficient \\ $\omega$ fan angular velocity (rad/s)
}

\section{SUBSCRIPTS}

ext external

int internal 


\author{
ip inlet primary circuit \\ is inlet secondary circuit \\ med medium \\ op outlet primary circuit \\ os outlet secondary circuit \\ $\mathrm{p} \quad$ primary circuit \\ prod food product \\ s secondary circuit \\ w water
}

\section{ORCID}

Michel Rivier (D) http://orcid.org/0000-0003-2318-5231

Martial Madoumier (D) http://orcid.org/0000-0002-7413-5472

\section{REFERENCES}

Affognon, H., Mutungi, C., Sanginga, P., \& Borgemeister, C. (2015). Unpacking postharvest losses in sub-Saharan Africa: A meta-analysis. World Development, 66, 49-68.

Bergman, T. L., Incropera, F. P., \& Lavine, A. S. (2011). Fundamentals of heat and mass transfer. Hoboken, $\mathrm{NJ}$ : Wiley.

Boroze, T., Desmorieux, H., Méot, J.-M., Marouzé, C., Azouma, Y., \& Napo, K. (2014). Inventory and comparative characteristics of dryers used in the sub-Saharan zone: Criteria influencing dryer choice. Renewable and Sustainable Energy Reviews, 40, 1240-1259.

Dabat, M. H., Blin, J., \& Rivier, M. (2010). Facing the challenge of energy and food in Burkina Faso. In Proceedings of the innovation and sustainable development in agriculture and food symposium, Montpellier, France, p. 7.

de Janvry, A., \& Sadoulet, E. (2000). Rural poverty in Latin America: Determinants and exit paths. Food Policy, 25, 389-409.

Dewan, A., Mahanta, P., Raju, K. S., \& Kumar, P. S. (2004). Review of passive heat transfer augmentation techniques. Proceedings of the Institution of Mechanical Engineers, Part A: Journal of Power and Energy, 218, 509-527.

Eiamsa-Ard, S., Kongkaitpaiboon, V., \& Promvonge, P. (2011). Thermal performance assessment of turbulent tube flow through wire coil Turbulators. Heat Transfer Engineering, 32, 957-967.
Hafsa, I., Cuq, B., Kim, S. J., Le Bail, A., Ruiz, T., \& Chevallier, S. (2014). Description of internal microstructure of agglomerated cereal powders using X-ray microtomography to study of process-structure relationships. Powder Technology, 256, 512-521.

Jacquet, P., Pachauri, R. K., \& Tubiana, L. (2012). Regards sur la Terre: Développement, alimentation, environnement : changer l'agriculture ? Paris: Armand Colin.

Kearney, J. (2010). Food consumption trends and drivers. Philosophical Transactions of the Royal Society B: Biological Sciences, 365, 2793-2807.

Kerkhof, P. J. A. M., \& Coumans, W. J. (2002). Drying: A fascinating unit operation. Chemical Engineering Journal, 86, 1-2.

Kyte, R., Clos, J., Amin, A. Z., \& Marangoly George, A. (2015). Sustainable energy. UN Chronicle, $L$ II, No 3.

Norme, N. (2011). Ergonomie-Manutention manuelle de charge pour soulever, déplacer et pousser/tirer-Méthodologie d'analyse et valeurs seuils. Norme française homologuée NF X35-109.

Proctor, D. (1994). Grain storage techniques: Evolution and trends in developing countries. Rome, Italy: Food and Agriculture Organization.

Rastoin, J. L. (2012). L'industrie agroalimentaire au coeur du système alimentaire mondial. In P. Jacquet, R. Pachauri, \& L. Tubiana (Eds.), Regards sur la terre. Développement, alimentation, environnement: Changer l'agriculture (pp. 275-285). Paris: Armand Colin. ISBN: 9782200275280.

Rivier, M., Sébastian, P., Goli, T., Raffray, G., \& Collignan, A. (2015). Heat transfer enhancement of a circular tube heat exchanger fitted with an elliptic shaped turbulator designed in the context of developing countries. Applied Thermal Engineering, 81, 92-101.

Webb, R. L. (1981). Performance evaluation criteria for use of enhanced heat transfer surfaces in heat exchanger design. International Journal of Heat and Mass Transfer, 24, 715-726.

Webb, R. L. (2005). Principles of enhanced heat transfer. Milton Park: Taylor \& Francis.

How to cite this article: Rivier $M$, Collignan A, Meot J-M, Madoumier M, Sebastian P. Modeling a process combining a cereal dryer with a bioenergy unit for equipment design in developing countries. J Food Process Eng. 2018;41:e12836. https://doi.org/10.1111/jfpe.12836 